\title{
Role of tandospirone, a 5-HT1A receptor partial agonist, in the treatment of central nervous system disorders and the underlying mechanisms
}

\author{
Xuefei Huang ${ }^{1, *}$, Jing Yang ${ }^{2, *}$, Sijin Yang ${ }^{3, *}$, Shousong Cao ${ }^{4}$, Dalian Qin' ${ }^{2}$ Ya Zhou ${ }^{1}$, \\ Xiaoli $\mathrm{Li}^{5}$, Yun $\mathrm{Ye}^{1,6}$ and Jianming $\mathrm{Wu}^{2}$ \\ ${ }^{1}$ Department of Clinical Pharmacy, School of Pharmacy, Southwest Medical University, Luzhou, Sichuan, 646000, China \\ ${ }^{2}$ Laboratory of Chinese Materia Medica, Department of Pharmacology, School of Pharmacy, Southwest Medical University, \\ Luzhou, Sichuan, 646000, China \\ ${ }^{3}$ Department of Cardiology and Neurology, Affiliated Traditional Chinese Medicine Hospital, Southwest Medical University, \\ Luzhou, Sichuan, 646000, China \\ ${ }^{4}$ Laboratory of Cancer Pharmacology, Department of Pharmacology, School of Pharmacy, Southwest Medical University, \\ Luzhou, Sichuan, 646000, China \\ ${ }^{5}$ Department of R\&D, Sichuan CREDIT Pharmaceutical Ltd., Luzhou, Sichuan, 646000, China \\ ${ }^{6}$ Department of Pharmacy, Affiliated Hospital of Southwest Medical University, Luzhou, Sichuan, 646000, China \\ *These authors have contributed equally to this work \\ Correspondence to: Jianming Wu, email: jianmingwu@swmu.edu.cn \\ Yun Ye, email: yeyun8622@163.com \\ Keywords: tandospirone; 5-HTIA receptor; Parkinson's disease; schizophrenia; mechanisms \\ Received: July 26, $2017 \quad$ Accepted: September 20,2017 Published: October 27, 2017 \\ Copyright: Huang et al. This is an open-access article distributed under the terms of the Creative Commons Attribution License \\ 3.0 (CC BY 3.0), which permits unrestricted use, distribution, and reproduction in any medium, provided the original author and \\ source are credited.
}

\section{ABSTRACT}

5-hydroxytryptamine (5-HT, serotonin) is an important neurotransmitter in the modulation of the cognitive, behavioral and psychological functions in animals and humans. Among the fourteen subtypes of 5-HT receptor, 5-HT1A receptor has been extensively studied. Tandospirone, an azapirone derivative with strong and selective agonist effect on 5-HT1A receptor, has been used for the treatment of anxiety disorders especially generalized anxiety disorder for decades. Recently, tandospirone showed the efficacy in relieving the syndromes of social anxiety disorder and posttraumatic stress disorder as well as in potentiating the effect of antidepressants in the treatment of depression in both preclinical and clinical studies. More impressively, the beneficial effect of tandospirone has been revealed on improvement of motor dysfunction of Parkinson's disease and cognitive deficits of schizophrenia either in monotherapy or in combination with other drugs. This review discusses the superiority of tandospirone in the treatment of the disorders and associated mechanisms in central nervous system from the literature.

\section{INTRODUCTION}

5-hydroxytryptamine (5-HT, serotonin), a biogenic amine, acts as a neurotransmitter and is discovered in wide variety of sites in the central and peripheral nervous system [1]. In brain, 5-HT neurons are mainly located in the raphe nuclei, whose relatively small number of neurons by projections innervate almost all brain areas as diverse as the limbic areas, cerebral cortex, basal ganglia, diencephalon and spinal cord. Thus, 5-HT binds to different receptors to execute significant effects on generation and modulation of cognitive, behavioral and psychological functions in the central nervous system (CNS) in animals and humans $[2,3]$. 
The distinct receptors of 5-HT comprise seven main families (5-HT1 to 5-HT7) with at least fourteen subtypes on the basis of their pharmacological responses to specific ligands, sequence similarities at gene and amino acid levels, gene organization and second messenger coupling pathways [4, 5]. Except for 5-HT3 receptor, which is assigned into the ionotropic receptor family, the rest of the hitherto identified receptors (5-HT1-2, 5-HT4-7) belong to the seven-transmembrane domain G-protein coupled receptor (GPCR) family [6]. Among these receptors, 5-HT1A receptor is thought to be the most important and has been extensively studied.

\section{5-HT1A RECEPTOR AND ITS AGONISTS}

\section{5-HT1A receptor}

The 5-HT1A receptor is the first subtype to be cloned and sequenced among all the serotonin receptors [7]. Analyzing the sequence of this genomic clone showed that $50 \%$ of amino acids were homologous with the $\beta 2$ adrenergic receptor in the transmembrane domain [8]. Furthermore, the 5-HT1A receptor gene is located on human chromosome 5q11.1-q13 and the encoded protein consists of 421 amino acids in human and mice while 422 amino acids in rats $[9,10]$. More importantly, it was accessible to visualize the sites of 5-HT1A receptor in various regions of brain at the sub-cellular level by the polyclonal antibodies [11]. The 5-HT1A receptor has been detected in limbic forebrain regions (e.g. hippocampus, raphe nuclei, amygdala) with high density, while in extrapyrimidal areas (e.g. basal ganglia, substantia nigra) with low density [12]. They are present on the soma and dendrites of 5-HT neurons isolated from raphe nuclei as presynaptical autoreceptors to inhibit the firing rate of 5-HT, and on postsynaptic neurons such as hippocampus and amygdala innervated by 5-HT neurons as heteroreceptors, where they also attenuate firing activity [13].

Since the crystal structures of 5-HT1B and 5-HT2B receptors have been well studied [14], a homology model of 5-HT1A receptor using the crystal structure of the 5-HT1B receptor (PDB ID: 4IAQ) was established to explore the structure basis of the stereoselectivity of a prototypical GPCR [15]. Using molecular interaction fingerprints, it was discovered that the agonist of 5-HT1A receptor could mobilize nearby amino acid residues to form a continuous water channel via molecular switches, while the antagonist of 5-HT1A receptor maintained stabilization in the binding pocket [16]. Although the accurately targeted site of 5-HT1A receptor by tandospirone is still unknown, it is rational to speculate that as a partial agonist of 5-HT1A receptor, tandospirone may act through forming a continuous water channel by mobilizing nearby amino acid residues.

\section{5-HT1A receptor agonists}

5-HT1A receptor agonists are one sort of the ligands which is able to activate the 5-HT1A receptors. According to different intrinsic activities, 5-HT1A agonists are clarified in two categories, namely full agonists such as 8-OH-DPAT, F-11440 and flesinoxan, as well as partial agonists such as ipsapirone, gepirone, buspirone and tandospirone [17-20]. Tandospirone is highly potent among partial agonists of 5-HT1A receptor and has a $K_{\mathrm{i}}$ value of $27 \pm 5 \mathrm{nM}$. Moreover, tandospirone is approximately two to three orders of magnitude less potent at 5-HT2, 5-HT1C, $\alpha 1$-adrenergic, $\alpha 2$-adrenergic and dopamine $\mathrm{D} 1$ and $\mathrm{D} 2$ receptors $\left(K_{\mathrm{i}}\right.$ values ranging from 1300 to $41000 \mathrm{nM}$ ) than at 5-HT1A [21]. Taken together, unlike other azapirones such as buspirone and ipsapirone with moderate-to-high affinity for the dopamine D2 receptor and $\alpha 1-$ adrenergic receptors, respectively, tandospirone has a potent and selective agonist effect on 5-HT1A receptor $[22,23]$. Specifically, tandospirone is characterized as a full agonist at 5-HT1A autoreceptors in the raphe nuclei as well as a partial agonist at postsynaptic 5-HT1A receptors in the forebrain areas receiving 5-HT input $[24,25]$.

Tandospirone Citrate (Sediel) was firstly synthesized by Dainippon Sumitomo Pharmaceuticals in 1980 and marketed in 1996 in Japan. It was available in China in 2004. In both countries, tandospirone was permitted for the treatment of anxiety disorder especially generalized anxiety disorder and anxiety associated with primary hypertension or peptic ulcer. Besides, tandospirone showed the efficacy in treating other CNS disorders such as depression, Parkinson's disease and schizophrenia in recent clinical and preclinical studies.

\section{TANDOSPIRONE IN THE TREATMENT OF CNS DISORDERS}

\section{Tandospirone in the treatment of anxiety disorders}

Anxiety disorders are the most common psychiatric disorders with lifetime prevalence up to $14 \%$, and have enormous burden on both society and individuals [26-30]. To date, there are seven recognized anxiety syndromes: panic disorder, agoraphobia, social anxiety disorder (SAD), generalized anxiety disorder (GAD), specific phobias, obsessive compulsive disorder (OCD) and post-traumatic stress disorder (PTSD). Pharmacological treatments for anxiety disorders are benzodiazepines, tricyclic antidepressant drugs, selective serotonin reuptake inhibitors (SSRIs), serotonin and noradrenaline reuptake inhibitors (SNRIs) and partial 5-HT1A receptor agonists. Because of low selectivity to diverse receptors, benzodiazepines (BZP) exert a series of adverse effects 
such as sedation, muscle relaxation, dependence and cognitive impairment $[31,32]$. SSRIs, a first-line treatment for many anxiety disorders, have received reduced acceptability in clinical practice due to a delayed onset of action, possible side effect of sexual dysfunction and even transiently increased anxiety [33].

Tandospirone showed anxiolytic action in variety of animal models $[25,34]$ and has been widely used in treatment of anxiety disorders especially in GAD [13, $35,36]$. Because of high selectivity to 5-HT1A receptor, tandospirone exerts definitely anxiolytic effect without benzodiazepines-like side effects such as sedation and muscle relaxation. Although the role of presynaptic 5-HT1A receptor is still uncertain, tandopirone shows its anxiolytic profile by activating postsynaptic 5-HT1A receptor coupled with $\mathrm{G}$-protein $\left(\mathrm{G}_{\mathrm{i} / \mathrm{o}}\right)$. On the one hand, tandospirone inhibits the activity of adenylate cyclase by coupling with $\mathrm{G}_{\mathrm{i} \alpha}$, resulting in reduction of cAMP formation and consequently inhibition of protein kinase A (PKA)-mediatied protein phosphorylation. On the other hand, it activates G-protein-gated inwardly rectifying potassium (GIRK) channels by releasing $\mathrm{G}_{\beta \gamma}$ subunits, leading to efflux of intracellular $\mathrm{K}^{+}$, hyperpolarization of targeted neurons and ultimately inhibition of neuronal activity [37-39]. As described above, postsynaptic 5-HT1A receptors are mainly located in the limbic areas such as hippocampus, amygdala as well as septum. Furthermore, tandospirone is capable of inhibiting the firing of hippocampal and lateral septal neurons by activating GIRK channels [24, 40, 41]. Thus, it may be anticipated that tandospirone alleviates anxiety through inhibiting the activity of hippocampus and amygdala which are associated with the induction of anxiety as well as the lateral septum referring to anxiety transmission. (Figure 1) However, short half-time and one- or two-week delayed onset are the major disadvantages of tandospirone in the treatment of anxiety [40].

Studies with double-blind, randomized clinical trials have proven that oral administration of tandospirone was equivalently effective as oral diazepam or clonidine in reducing preoperative anxiety in patients with elective otolaryngologic surgery $[42,43]$. In the rat contextual conditioned fear stress model, tandospirone or SSRIs (e.g. paroxetine, fluvoxamine, citalopram) significantly inhibited the conditioned freezing in a dose-dependent manner, respectively, and the combination therapy was addictive for fluvoxamine facilitating anxiolytic effect of tandospirone via CYP3A4 inhibition [44-46]. Moreover, tandospirone exhibited therapeutic potential for facilitating fear extinction to alleviate anxiety, and the effect was mediated by enhancing cortical dopamine neurotransmission indirectly via the ventral tegmental area (VTA)-hippocampus dopaminergic loop and improving synaptic efficacy in the extinction processes in the animal model of PTSD [47, 48]. More recently, tandospirone has been proven to be safe and effective and it appeared non-inferior to sertraline for treating SAD in youths in an eight-week randomized open-label trial [49]. Taken together, tandospirone may be an alternative agent in relieving anxiety in the treatment of PTSD and SAD.

\section{Tandospirone in the treatment of depression}

Depressive disorder (major and minor) is a chronic, highly recurrent, and debilitating mental disease with highly suicide rate and has a lifetime prevalence of up to $20 \%$ [50]. Depression was the leading cause of disability globally by a recent WHO announcement [51]. Over the past 50 years, pharmacological approaches for the treatment of depression have updated from tricyclic antidepressants and monoamine oxidase inhibitors, to SSRIs and SNRIs. Nonetheless, these advances are far from optimistic because of suboptimal treatment response and low remission rates. For instance, the pooled response rates were $37 \%$ and $54 \%$ for placebo and drug, respectively, in a meta-analysis of 182 antidepressant randomized controlled trials (RCTs, $\mathrm{n}=36,385$ ) [52].

The dysfunction of 5-HT system, such as 5-HT deprivation, has been widely accepted to play a crucial role in the pathogenesis of depression [53]. Tandospirone had shown its antidepressant effect in several forced swimming tests in an animal model of depression [5457]. Acute administration of tandospirone decreased the releasing of 5-HT in the nerve terminal region, the dendrites and cell body region, while chronic treatment induced desensitization of somatodendritic 5-HT1A autoreceptors, relieving 5-HT neurons from autoreceptormediated self-inhibition, eventually tonically activating of 5-HT neurons and counteracting the serotonergic deficit. On the other hand, the sensitivity of postsynaptic 5-HT1A receptors was non-altered even after repeated treatment of tandospirone $[13,40]$. It is putative that the duration of desensitizing of presynaptic 5-HT1A autoreceptors in the raphe nuclei is sufficient for tandospirone's antidepressant activity, and it also explains the late onset of action of tandospirone treatment. Several clinical studies have proven that co-treatment of tandospirone and SSRIs synergistically facilitated the desensitization of 5-HT1A autoreceptors, thus exhibiting a more rapid onset of action and/or augmenting the antidepressant actions [44, 58, 59]. Furthermore, an increasing body of research evidence has shown that the antidepressant activity of tandospirone may be associated with other pharmacodynamics effect. Clinical studies showed that tandospirone potentiated the efficacy of fluoxetine, a SSRI, in the treatment of major depressive disorders. In animal studies, tandospirone augmented fluoxetine-induced increase in extracellular dopamine level in dialysates of medial frontal cortex in rat with $200 \%$ or $380 \%$ of basal levels for fluoxetine alone or for fluoxetine in combination with tandospirone, respectively [60]. Furthermore, increased hippocampal neurogenesis is implicated in the action mechanism 
of antidepressants [61]. In two recent studies, chronic treatment of tandospirone reversed the decrease in the density of doublecortin (DCX)-positive cells, a marker protein of newborn neurons, in the dentate gyrus of hippocampus in intermittent social defeat rat or directly increased the number of the DCX-positive cells in normal rats, indicating that chronic tandospirone treatment exerted antidepressant action also via increasing hippocampal neurogenesis $[57,62]$. In terms of energy metabolism, the footshock stress-induced increment of extracellular lactate concentrations in the prefrontal cortex of rats was suppressed by chronic treatment of tandospirone, but it is still in debate whether this effect of tandospirone is related to ameliorating anxiety and depression or not [63].

A randomized, controlled clinical trial for evaluation of the efficacy of clomipramine alone and in combination with tandospirone or diazepam for 6 weeks in 36 untreated outpatients with major depressive disorder was conducted, and no statistically significant differences in improvement of major depressive disorders were observed in the terms of the Hamilton Depression Rating Scale and the Hamilton Anxiety Rating Scale scores among the three groups. However, tandospirone may induce early antidepressant effects in augmentation of clomipramine [64]. Given the small sample capacity, a larger randomized controlled trial is needed to confirm the conclusion.
Besides, the superiority of tandospirone in the treatment of depression also lies in following circumstances. Primarily, antidepressants such as tricyclic antidepressants with anticholinergic activity may induce severe intestinal dysfunction and delirium, while monotherapy of tandospirone significantly ameliorated the depressive mood, agitation and anxiety of senile patients with dementia with little anticholinergic activity [65]. Secondly, eighty to ninety percent of patients with major depression are suffering from sleep disturbance, which is widely accepted as a risk factor and/or prodromal symptom of depression [66-69], while tandospirone could markedly improve sleep disturbance induced by Adrenocorticotropic hormone (ACTH) in a rat model [70]. Finally, since SSRIs are still the first choice for the treatment of patients with depression, the side effect of SSRIs could not be ignored. A case report in Japan showed systematic administration of tandospirone could effectively treat paroxetine-induced bruxism by increasing dopamine release in the prefrontal cortex [71].

\section{Tandospirone in the treatment of Alzheimer's disease}

Alzheimer's disease (AD) is one of the most common neurodegenerative diseases and characterized

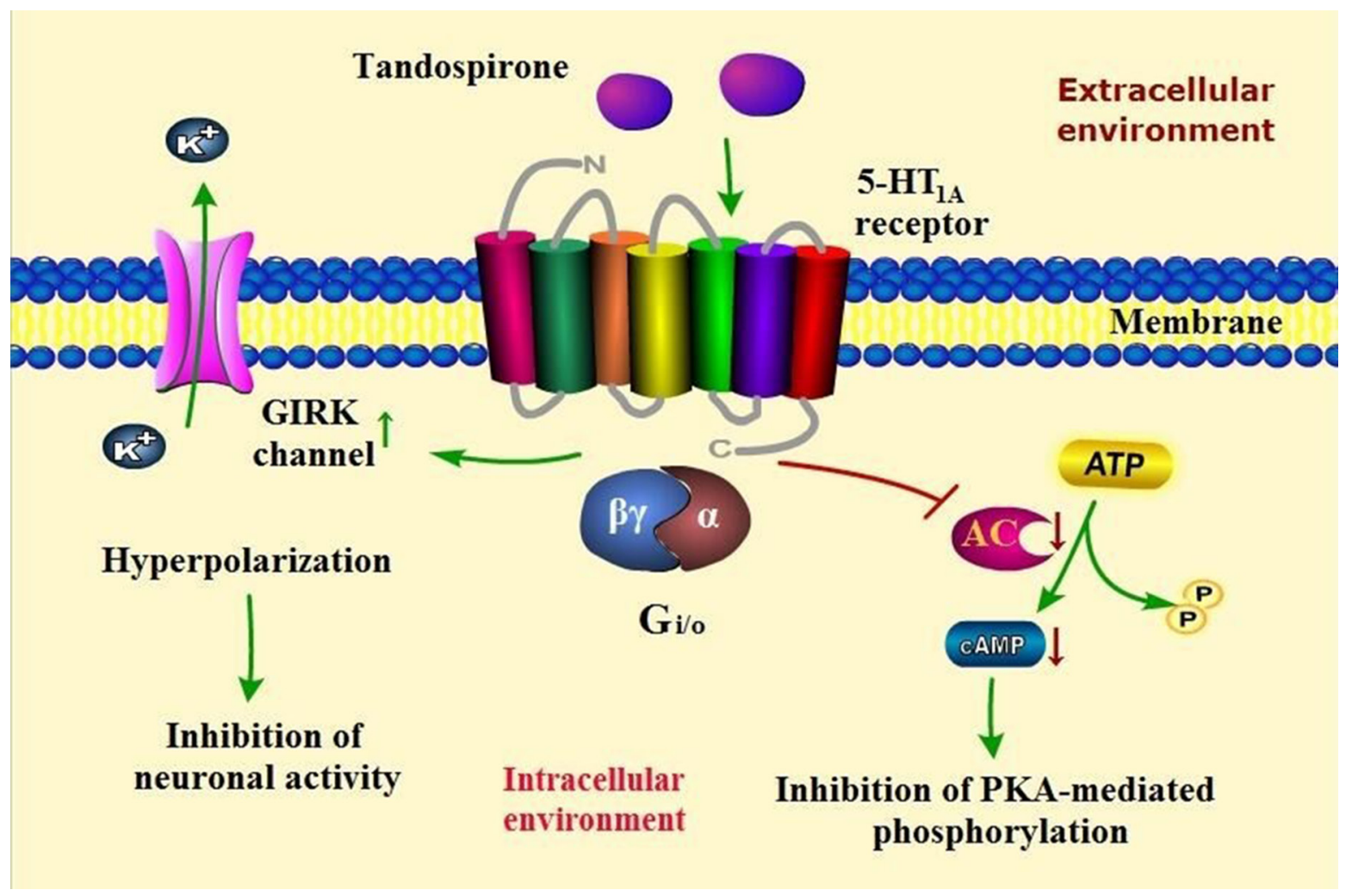

Figure 1: A proposed scheme of tandospirone and its signal transduction pathway in the treatment of anxiety disorders. Tandospirone activats postsynaptic 5-HT1A receptor coupled with G-protein $\left(\mathrm{G}_{\mathrm{i} / \mathrm{o}}\right)$, resulting in inhibition of protein kinase A (PKA)mediated protein phosphorylation and neuronal activity. 
by impairments in cognition and behavior, eventually resulting in decline in activities of daily living. Nearly $80 \%$ of patients with AD have suffered behavioral and psychological symptoms of dementia (BPSD) in the course of the illness. The International Psychiatric Association defines Behavioral and Psychological Symptoms of Dementia (BPSD) as non-cognitive symptoms such as behaviors (e.g. agitation, aggression, wandering, and screaming) and psychiatric disturbances (e.g. hallucination, delusion, depression, anxiety, and insomnia). Classical drug therapy for AD consists of acetylcholinesterase (AChE) inhibitors (e.g. donepezil and galantamine etc.) and N-methyl-D-aspartate (NMDA) receptor antagonist (e.g. memantine), these drugs have shown moderate efficacy in relieving cognitive and functional symptoms. However, the biggest challenge for $\mathrm{AD}$ treatment is to discover and develop novel drugs that could substantially slow disease progression or even cure the disease. For the treatment of BPSD, common psychotropic agents and atypical neuroleptics only have moderate efficacy with increased mortality [72], therefore, it is imperative to develop safer and more effective agents.

Together with dysfunction of cholinergic and glutamatergic system, abnormal serotonergic system is also thought to contribute to learning and memory impairment in AD patients. It was found decreased radioligand $\left[{ }^{11} \mathrm{C}\right]$ WAY100635, a potent antagonist of 5-HT1A receptor, binding to 5-HT1A receptor in hippocampus and cortex in patients with $\mathrm{AD}$ compared with healthy volunteer. On the other hand, there were negative correlations between 5-HT1A density and aggressive behavior of AD patients from a post-mortem study [73]. Taken together, 5-HT1A receptor antagonists were speculated to be effective for the treatment of memory impairment in $\mathrm{AD}$ patients [74]. However, none of such 5-HT1A receptor antagonists were available for clinical use up to date. A preliminary openlabel study showed that tandospirone was effective in the treatments of BPSD in thirteen outpatients with DSM-IV of AD or vascular dementia [75]. Significant improvement of psychological symptoms such as depression, anxiety and irritability/lability and behavioral symptoms such as agitation and aggression without serious adverse effects were observed, suggesting that tandospirone is a promising medicine for the treatment of BPSD with remarkable tolerability and improvement of cognitive and memory deficits, and its effectiveness may not only be simply correlated with the density or binding potential to 5-HT1A receptors [75].

\section{Tandospirone in the treatment of Parkinson's disease}

Parkinson's disease (PD) is a prevalent, lateonset neurodegenerative disease, which is due to lesions of nigro-striatal dopamine neurons or depletion of dopamine. PD has a wide spectrum of clinical features including extrapyramidal motor symptoms (e.g. akinesia/ bradykinesia, tremor, rigidity and postural defect) as well as various non-motor symptoms (e.g. cognitive impairment, mood disorders, autonomic dysfunction and sleep disorders) [76]. After nearly 40 years, the dopamine precursor L-3,4-dihydroxyphenylalanine (levodopa or L-DOPA) is still the golden-standard treatment for PD. Other antiparkinsonian agents are dopamine D2/D3 agonists (e.g. bromocriptine, cabergoline, pramipexole), dopamine releasers (e.g. amantadine), along with muscarinic acetylcholine $(\mathrm{mACh})$ receptor antagonists (e.g. trihexyphenidyl and biperidene). Inhibitors of monoamine oxidase-B (MAO-B) (e.g. selegiline) or catechol-O-methyltransferase (COMT) are useful adjunctive drugs to potentiate the effect of L-DOPA. However, there are still clinical unmet needs, such as reduction of levodopa-induced dyskinesias (LIDs) and motor fluctuation (e.g. on-off or wearing-off phenomena) after chronic treatment of L-DOPA, non-motor symptoms (e.g. cognitive impairments and affective disorders), as well as lack of substitutes for L-DOPA.

Since 5-HT1A receptor was discovered to be involved in regulating the motor functions such as extrapyramidal motor symptoms, tandospirone has shown antiparkinsonian action in both preclinical studies and clinical trials. Tandospirone improved walking stability and activity of daily life in approximately $40 \%$ patients with PD [77]. An eight-week open clinical study revealed that tandospirone exhibited antiparkinsonian effect evaluated by Simpson Angus Extrapyramidal Symptom Scale (SA-EPS) scores [78]. Furthermore, tandospirone had been reported to ameliorate pure akinesia in a patient with resistance to noradrenergic precursor L-threo-DOPS [79]. Along with the clinical studies, numerous preclinical studies have been conducted and shown that tandospirone induced contralateral rotation behaviors in dopaminergic hemilesioned rats evoked by 6-hydroxydopamine (6-OHDA), ameliorated haloperidol-induced catalepsy and bradykinesia, and reserpine-induced hypolocomotion in dopamine-depleted rats [80-83]. It should be noted that the ameliorative effect of tandospirone in above animal models was nearly fully antagonized by pre/ co-administration of WAY-100635, a potent 5-HT1A receptor antagonist, but not haloperidol, a D2 antagonist, indicating that the antiparkinsonian effect of tandospirone is associated with direct activation of 5-HT1A receptor and independent of dopaminergic activity. Intrastriatal injection of 5-HT at doses compatible to those of dopamine (5-HT, 25-100 $\mu \mathrm{g}$; dopamine, 50-100 $\mu \mathrm{g}$ ) caused a contralateral circling behavior in rats, implying that the striatal 5-HT1A receptors played a role in antiparkinsonian effects [84]. Moreover, inactivation of 5-HT neurons by $p$-chlorophenylalanine did not alter the antibradykinesia effect of 8-OH-DPAT [83]. In general, it was the action of postsynaptic 5-HT1A receptor that tandospirone elicited its antiparkinsonian effects. 
Furthermore, several studies have indicated that there was an increase of releasing glutamate in the regions such as entopeduncular nucleus and striatum as well as an enhancement of Fos expression in the shell and core regions of nucleus accumbens, dorsolateral striatum, and lateral septal nucleus in dopaminergic hemilesioned rats or dopamine-depleted rats [85]. 5-HT1A receptor agonists inhibited the cortico-striatal glutamate pathway and reduced extracellular glutamate levels in the striatum, and tandospirone significantly reduced haloperidol-induced Fos expression in the dorsolateral striatum $[86,87]$. Thus, it was proposed that after activating the postsynaptic receptors, tandospirone inhibited cortico-striatal glutamate pathway, reduced the releasing of glutamate and decreased the activity of glutamate neurons and the expression of Fos, resulting in the effect of ameliorating motor dysfunction.

Unlike the antiparkinsonian effect, tandospirone showed only limited effect for alleviating L-DOPAinduced dyskinesia (LID) in several studies. Tandospirone has been tested in 10 patients with LID, and results showed that L-DOPA-induced dyskinesia was considerably alleviated in half of tested patients but Parkinson-like features were slightly worsened in 6 out of 10 patients. In other words, the effect of tandospirone of ameliorating LID was probably at the expense of worsening parkinsonism [88]. In a recent study, tandospirone attenuated L-dopa induced peak abnormal involuntary movements (AIM) scores by about $40 \%$ at the highest dose $(2.5 \mathrm{mg} / \mathrm{kg})$ but failed to significantly reduce the total AIMs scores in one testing session [89]. In the same study, tandospirone $(0.16$ $\mathrm{mg} / \mathrm{kg}, 0.63 \mathrm{mg} / \mathrm{kg}$, and $2.50 \mathrm{mg} / \mathrm{kg}$ ) did not improve the effect of L-dopa in cylinder and rotational behavior test, and decreased the effect of L-dopa in rotarod performance at the highest dose. Given the limited literature, more studies should be conducted to define the definite effect of tandospirone on LID.

Nearly $40 \%$ patients with PD also suffer depression (major or minor), and anxiety (e.g. GAD, panic disorder). Thus, depression and anxiety are common in the patients with PD. As stated above, tandospirone is an effective and safe anxiolytic and antidepressant, so it is reasonable to use tandospirone for the treatment of affective disorders in the patients with PD $[90,91]$.

\section{Tandospirone in the treatment of schizophrenia}

Schizophrenia is a holergasia with unknown etiology and characterized by positive symptoms (e.g. hallucinations, delusion, and excitation), negative symptoms (e.g. apathy, social and emotional withdrawal), cognitive impairments, and mood disturbances (e.g. anxiety and depression) $[92,93]$. Classical antipsychotics (e.g. phenothiazine, butyrophenone, and haloperidol) mainly blocking D2 receptor have contributed to control of positive symptoms of schizophrenia but induced severe extrapyramidal side effects (EPS). Since atypical antipsychotics (e.g. clozapine, risperidone, ziprasidone, perospirone, olanzapine, and quetiapine), the second generation of antipsychotics, became the first line treatment for schizophrenia, positive symptoms, negative symptoms, and typical antipsychotics induced EPS have been ameliorated. Nonetheless, there are still clinical unmet in the treatment of schizophrenia, such as cognitive dysfunction, affective disorders, and antipsychoticinduced EPS.

Apart from beneficial effect on affective disorders and EPS demonstrated above, tandospirone also has therapeutic potential for improvement of schizophreniaassociated cognitive deficits. Cognitive functions including memory, executive function and attention are impaired in most patients with schizophrenia, and secondary verbal memory and executive function have been reported to be predominant index for outcome measurement [94, 95]. Some studies have shown that atypical antipsychotics modestly improve cognitive function with various mechanisms, and a 5-HT1A-dependent mechanism may be involved to promote the release of dopamine from the cortex [96, 97]. Thus, it is logical to postulate that 5-HT1A agonists have beneficial effect on improvement of cognitive function. Indeed, numerous clinical studies have shown that chronic adjunctive treatment of tandospirone with typical or atypical antipsychotics significantly improved the cognitive function in patients with schizophrenia. Specifically, a preliminary openlabel clinical study revealed the beneficial effect of combined use of tandospirone (30 mg/day) and moderate doses of haloperidol in enhancing attentive function in schizophrenia patients [98]. Subsequently, a similar study with 11 patients with schizophrenia and same number of healthy volunteers as control indicated that the addition of tandospirone with small to moderate doses of haloperidol improved secondary verbal memory in the patients with schizophrenia [99]. In another study, the effectiveness of tandospirone for ameliorating cognitive impairment, especially for executive function and secondary verbal memory, was also confirmed in 26 patients with schizophrenia after tandospirone was added to ongoing treatment with typical antipsychotic drugs for 6 weeks [100]. In two single case reports, tandospirone improved cognitive performance and quality of life when combined with atypical antipsychotics olanzapine or perospirone, respectively [101, 102]. However, it was also reported that acute (60 min) administration of tandospirone impaired explicit verbal memory in healthy volunteers in a dosedependent manner [103]. The treatment regimen (acute $v s$. chronic) and/or subjects studied (health controls $v s$. schizophrenia patients) may account for the discrepancy between these studies.

Data from animal studies also revealed the superiority of tandospirone in the treatment of schizophrenia. Novel object recognition (NOR) deficits 
could be induced by subchronic treatment of phencyclidine (PCP), a N-methyl-D-aspartate (NMDA) receptor antagonist, and NOR is an analog of declarative memory and its deficits were often observed in animals and patients of schizophrenia with cognitive impairment [104]. Tandospirone alone or co-treatment with lurasidone for 15 days significantly reversed PCP-induced NOR deficits [105]. There was an increased release of 5-HT in the cortex or 5-HT1A receptor binding potential in the medialand dorsolateral-frontal cortex, when PCP was acute or subchronic administrated [106, 107]. Similar findings were also confirmed in patients with schizophrenia by postmortem and positron emission tomography [108, 109]. The evidence suggests that tandospirone could reverse NOR deficits, probably related to its 5-HT1A agonist properties, diminishing 5-HT release, and normalizing 5-HT1A receptor binding potential. Besides, tandospirone improved cognitive deficits by monotherapy or in combination with blonanserin, an atypical antipsychotic, assessed by executive function in marmosets using object retrieval with detour (ORD) task [110]. This study also revealed that the D1 receptor agonist SKF-81297 improved the marmosets performance in ORD task. It has also been reported that tandospirone increased the extracellular dopamine level in the prefrontal cortex [60]. Thus, it is possible that tandospirone actives the 5-HT autoreceptor in the raphe nuclei, inhibits the firing of 5-HT neurons, disinhibits the DA neurons, increases the release of DA, and ultimately improves the executive function. Interestingly, augmentation use of tandospirone and haloperidol showed no beneficial advantages in executive function in this study while the combination treatment had shown its beneficial effect on memory function in clinical trial as stated above $[98,99,110]$. Furthermore, another NMDA receptor antagonist, dizocilpine (MK-801), were transiently administrated to the neonatal rats and suppressed stress-induced increment of lactate production, and chronic treatment of tandospirone attenuated the suppressive effect induced by dizocilpine via elevating lactate production [111]. These data indicate that lactate production may play an important role in ameliorating cognitive impairment in schizophrenia.

Study also showed that tandospirone decreased locomotor activity in the rats with or without dizocilpine treatment but the efficacy was only observed with the dose of tandospirone at $5 \mathrm{mg} / \mathrm{kg}$ not at the low dose of $0.05 \mathrm{mg} / \mathrm{kg}$, indicating that tandospirone at high dose could be effective to relieve positive symptoms of schizophrenia [112]. It is of interest that this inhibitory effect of tandospirone could be augmented by acute administration of 5-HT1A antagonist WAY 100635, suggesting the underlying mechanism may be associated to its metabolites or other neurotransmitter systems. Tandospirone is metabolized to 1-(2-pyrimidinyl)piperazine (1-PP) in rodents and humans, and as an $\alpha 2-$ adrenoceptor antagonist, 1-PP induced hypolocomotion in mice and rats $[113,114]$. Therefore, it is possible that the $\alpha 2$-adrenoceptor-antagonistic effect of 1-PP was responsible for the efficacy of tandospirone in decreasing locomotion. However, in the same study, tandospirone exacerbated dizocilpine-induced prepulse inhibition (PPI) of the acoustic startle response. This phenomenon was observed by measuring the deficits in sensorimotor gating and frequently occurred in patients with schizophrenia. Another study showed that tandospirone suppressed impulsive action in a dose-dependent manner, while higher impulsivity is often observed in the patients with schizophrenia [115]. Moreover, the suppressive effect of tandospirone could not be reversed by WAY 100635 either at $0.3 \mathrm{mg} / \mathrm{kg}$ or higher dose $1 \mathrm{mg} / \mathrm{kg}$, in contrast, WAY100635 even strengthened the suppressive effect of tandospirone. It is speculated that as a partial agonist for 5-HT1A receptor, tandospirone may also act as an antagonist, however, there is no clear evidence to prove it so far. In summary, tandospirone could be a promising candidate for the treatment of schizophrenia.

\section{ASSOCIATED MECHANISM OF TANDOSPIRONE IN THE TREATMENT OF CNS DISORDERS}

\section{Activating signal transduction pathway}

It is generally believed that tandospirone acts on 5-HT1A receptor in membrane of dorsal raphe nucleus and limbic area to activate G-protein-activated inwardly rectifying $\mathrm{K}^{+}$(GIRK) channels. This process will arouse some changes as follows: on the one hand, hyperpolarization of target neurons by potassium efflux and consequently inhibition of neuronal firing [116]; on the other hand, inactivation of adenylyl cyclase for subsequently inhibition of the cAMP-PKA cascade. Alternatively, tandospirone increases the phosphorylation of extracellular signal-regulated kinase (ERK) in both hypothalamic paraventricular nucleus and the dorsal raphe nucleus, and these responses could be blocked by the 5-HT1A antagonist WAY 100635, suggesting the involvement of mitogen-activated protein (MAP) signal pathway [117]. Study has shown that chronic treatment of tandospirone desensitized 5-HT1A receptor on the dorsal raphe nucleus and hypothalamic paraventricular nucleus but not hippocampus of brain [118], the ERK signal pathway may underlie the difference.

\section{Elevating dopamine level}

Tandospirone treatment $(5 \mathrm{mg} / \mathrm{kg})$ ameliorated the synaptic dysfunction before and after extinction trials in a rat model of juvenile stress [aversive footshock (FS) rat] [47]. Extinction processes contains extinction training and extinction retrieval, which are associated with synaptic efficacy in the hippocampal CA1 and medial prefrontal 
cortex (mPFC), respectively. Tandospirone increased extracellular dopamine levels in $\mathrm{MPFC}$ after extinction retrieval in the non-FS rats (control). Based on the fear extinction study, the effectiveness of tandospirone for the treatment of patients with anxiety especially PTSD, may rely on improving synaptic efficacy associated with extinction processes by elevating dopamine release [47]. Simultaneous administration of tandospirone and fluoxetine significantly increased dopamine release compared to monotherapy in the medial frontal cortex of rats measured by microdialysis. In addition, preadministration or local perfusion of WAY 100635 suppressed tandopirone-induced increment of extracellular DA. These results suggest that tandospirone elevates extracellular dopamine by stimulating 5-HT1A receptors in $\mathrm{mPFC}$ and it may have potential to modulate refractory depression in addition to SSRI [60]. Tandospirone showed beneficial effects on executive function in marmosets in ORD task, and increased extracellular dopamine level in mPFC in previous study [110]. In addition, it is hypothesized that 5-HT1A receptor agonist improves cognitive function in patients with schizophrenia through enhancement of cortical dopamine neurotransmission [119-121]. In the same study, the D1 receptor agonist SKF 81297 improved marmosets' performance in ORD task [110]. Taken together, tandospirone has beneficial effect on the improvement of cognitive dysfunction in patients with schizophrenia and the possible mechanistic action may be associated with increased dopamine neurotransmission (Figure 2).

\section{Maintaining hippocampal neurogenesis and synaptic plasticity}

Chronic treatment of tandospirone reversed the decrease in the density of doublecortin (DCX)-positive cells in the dentate gyrus of hippocampus both in patients with major depressive disorder and stress-induced social defeat rats $[57,62]$. However, no difference was observed between vehicle and tandospirone-treated groups using marker Ki-67 in the animal study [62]. Adult hippocampal neurogenesis had been reported to relate to stress-induced pathophysiology of depressive disorder and one of the mechanistic actions of antidepressants such as SSRI $[122,123]$. Moreover, hippocampal neurogenesis plays a role in maintenance of the function of dentate gyrus and hippocampal circuitry, and cognitive function affected by AD [124]. Thus, tandospirone has beneficial effects on anxiety and depressive disorders as well as $\mathrm{AD}$, from the standpoint of hippocampal neurogenesis.

Tandospirone treatment showed no reduction in hippocampal long-term potentiation (LTP) compared to diazepam in mossy fiber-CA3 and perforant path-dentate gyrus synapses, except in Schaffer collateral-CA1 [125]. Hippocampal synaptic plasticity such as LTP is regarded as the electrophysiological basis of synaptic mechanism and the molecular basis of learning and memory [126].

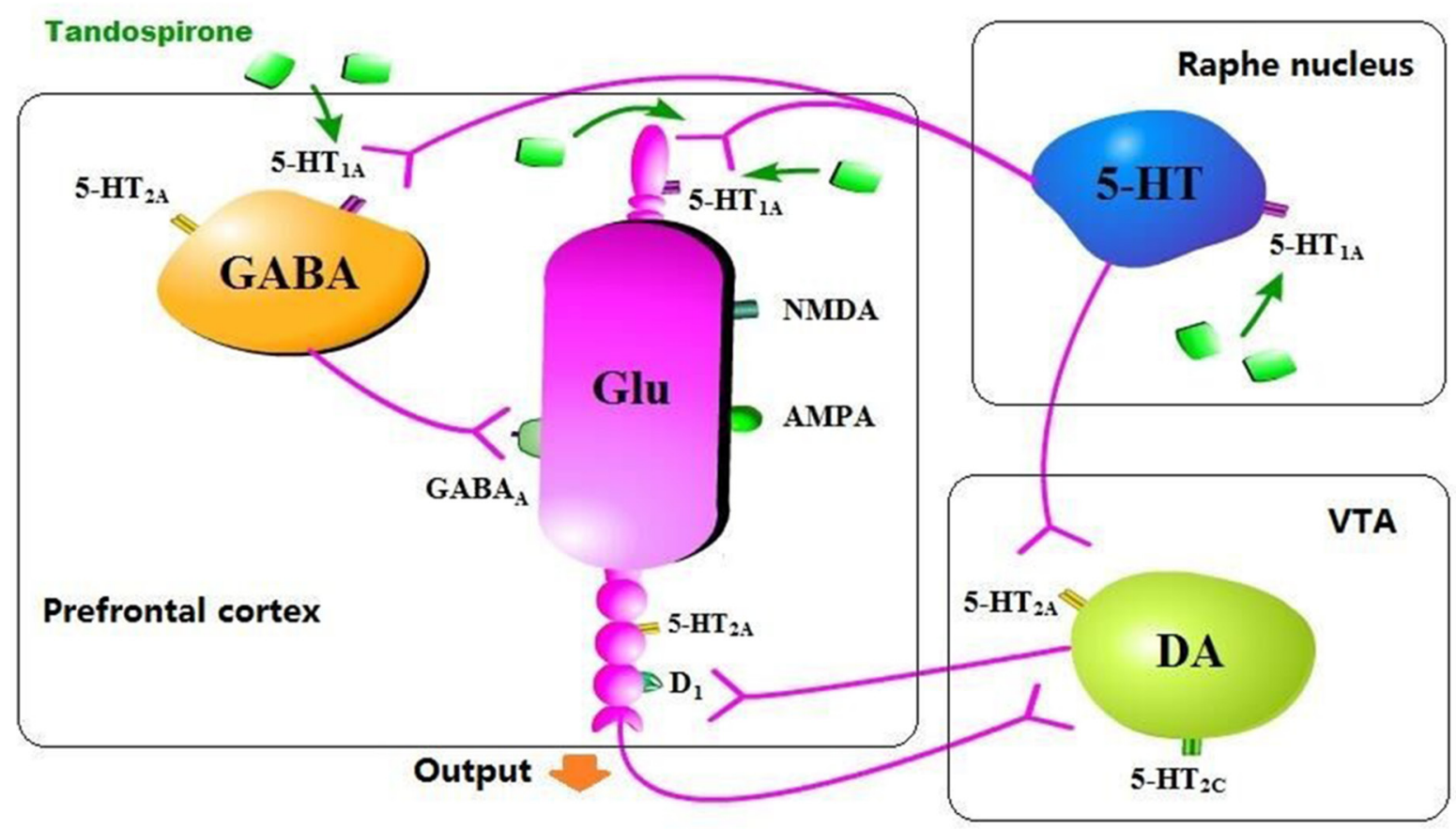

Figure 2: The underlying mechanism of tandospirone in elevating dopamine level. Tandospirone activates 5-HT1A receptor in the raphe nucleus or mPFC, directly or indirectly excites and/or disinhibits DA neuron in VTA and increases DA release. 
These facts indicate that tandospirone is superior to benzodiazepine in the improvement of learning and memory impairment.

\section{Normalizing lactate production}

Although glucose is the major substrate for energy supply in the brain, lactate gradually shows its significance in energy metabolism in acute neural activation [127, 128]. According to the astrocyte-neuron lactate shuttle hypothesis, glucose supplied from the blood circulation is converted to lactate by astrocytes accompanied by glutamate uptake. Specifically, the activation of nerve cells leads to the release of the neurotransmitter glutamate. Glutamate is actively taken up into astrocytes by glutamate transporters (GLT-1) and is converted into glutamine. The uptake of glutamate into astrocytes increases glucose uptake from surrounding capillaries via glucose transporters and aerobic glycolysis. Lactate is then released to the extracellular space and utilized by activated neurons (Figure 3). More importantly, recent studies suggested that the brain prefers lactate over glucose for energy supply in the state of acute neural activation and lactate has definitely neuroprotective effect [129131]. Both acute and chronic treatment of tandospirone attenuated footshock stress-induced extracellular lactate concentrations (eLAC) increment in $\operatorname{mPFC}[63,132]$. Acute treatment of tandospirone reduced the firing rate of 5-HT neurons in the raphe nuclei, subsequently reduced 5 -HT release in the $\mathrm{mPFC}$, and consequently provided a negative feedback to the raphe nuclei, which could reduce energy demand in the state of neural activation $[13,132]$. On the other hand, chronic administration of tandospirone leads to desensitize the somatodendritic 5-HT1A autoreceptor and normalizes 5-HT releasing. As a 5-HT1A partial agonist, tandospirone also activates postsynaptic receptor, leading to counteracting the increased 5-HT concentrations, resulting in decreasing

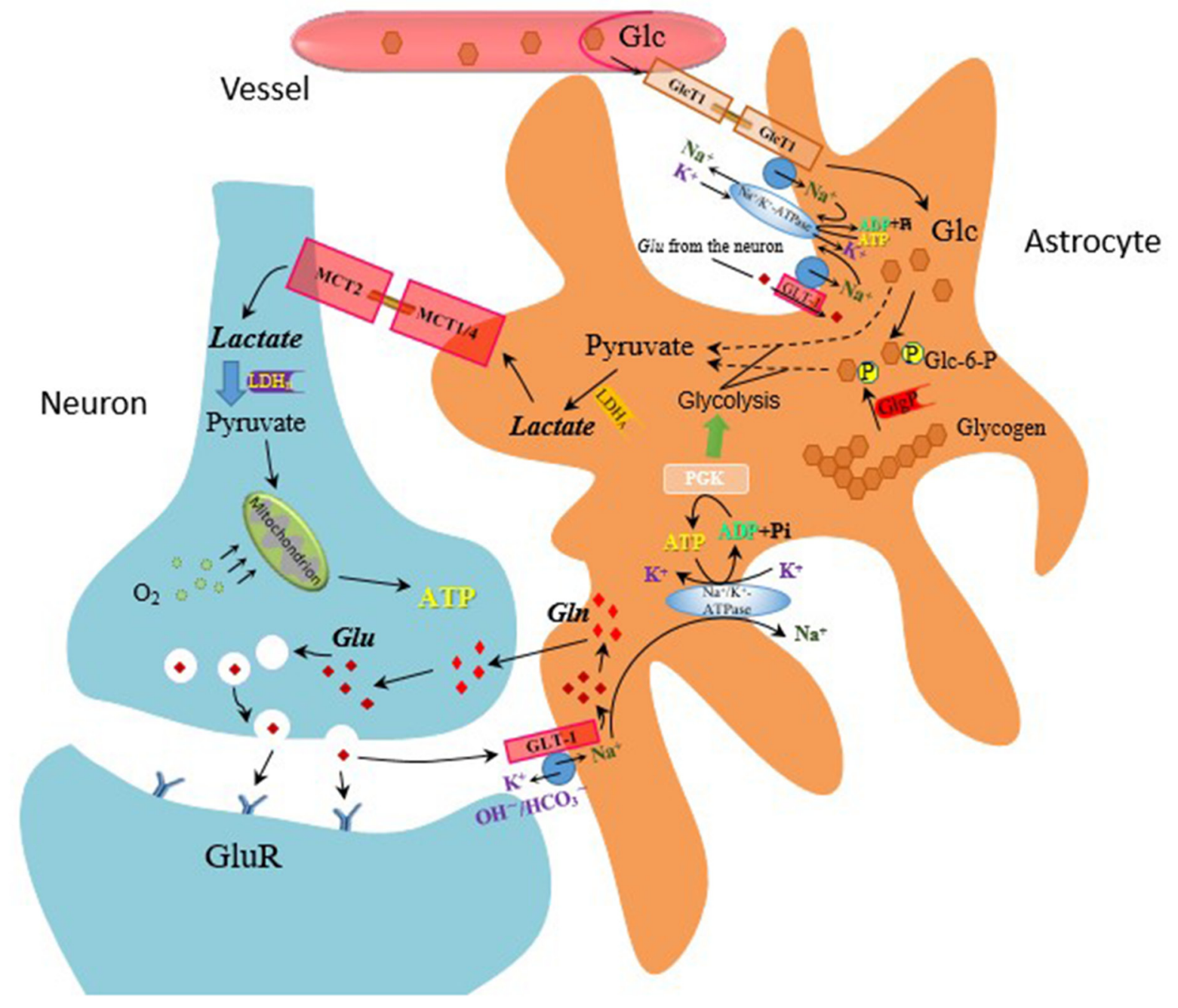

Figure 3: The astrocyte-neuron lactate shuttle hypothesis-mechanism of lactate production on glutamate release. Glucose (Glc) from the blood circulation is converted to lactate by astrocytes accompanied by glutamate (Glu) uptake. 
energy demand in the mPFC. Since lactate is produced in a neural activity-dependent manner, decreased energy demand results in decrease of eLAC in footshocked rats. However, 1-(2-pyrimidinyl)- piperazine (1-PP), a metabolite of tandospirone exerts an $\alpha 2$-adrenoceptor antagonist effect [114] and increases the firing rate of 5-HT neurons, it may compromise the beneficial effect of tandospirone. As stated above, the production of lactate is also mediated by glutamate uptake. In addition, infusion of 5-HT1A agonists into the PFC results in reversing NMDA receptor antagonist-induced glutamate release [133]. Thus, it is speculated that the effect of tandospirone on decreasing footshock-induced increment of eLAC may be mediated by inhibition of glutamate release.

Furthermore, tandospirone reversed the decrease of eLAC induced by transient blockade of NMDA antagonist in response to stress [111]. NMDA receptor antagonists (MK-801 or PCP) led to long-term impairment of cognitive function in schizophrenia in rodents determined by the delayed spatial alteration task and set-shifting task $[134,135]$. Besides, the NMDA receptor antagonists also enhance neuronal apoptosis and neuronal degeneration, and reduce spine density in the frontal cortex [136, 137]. These facts suggest that MK-801 in decrease of eLAC level may be due to decreasing the numbers of neurons and/or astrocytes. Besides, systemic administration of 5-HT1A receptor agonists could inhibit the action potentials of GABA neurons, consequently disinhibit glutamate neurons resulting in glutamate release and increment of eLAC [119, 138] (Figure 2). It is putative that the effect of tandospirone on restoration of MK801-induced eLAC decrease in response to physical stress may be mediated by modulation of glutamatergic neurotransmission via 5HT1A receptors on GABAergic interneurons. Interestingly, a completely opposite result was reported by a study in 2014, which showed that high dose of tandospirone $(5 \mathrm{mg} / \mathrm{kg}$ ) suppressed footshockinduced eLAC elevation in rats treated with MK-801 [139]. One of the explanations for the different results could be the timing and regimen differences with MK-801 administration, e.g. acute vs chronic administration and/or at neonatal vs young adult rats. Taken together, the effects of tandospirone on brain energy metabolism especially in lactate production may be a novel mechanism in the treatment of Schizophrenia.

\section{CONCLUSION}

Tandospirone, a partial 5-HT1A receptor agonist, has been commonly used in the treatment of anxiety disorders, especially in China and Japan. This review provides evidence that tandospirone has beneficial effect in the treatment of other CNS disorders such as Alzheimer's disease, Parkinson's disease, and schizophrenia. Along with better understanding of the associated mechanisms of tandospirone in the treatment of these diseases, it is anticipated that tandospirone could be more frequently utilized in the treatment of the patients with CNS disorders besides anxiety.

\section{Author contributions}

Xuefei Huang, Jianming Wu, Sijin Yang and Yun Ye conceived and designed the review; Xuefei Huang, Jing Yang, Shousong Cao, Sijin Yang, Dalian Qin, Ya Zhou, and Xiaoli Li reviewed the literature; Xuefei Huang, Jing Yang, Jianming Wu, Yun Ye, Sijin Yang and Shousong Cao wrote the manuscript.

\section{ACKNOWLEDGMENTS AND FUNDING}

This work was supported by the Science and Technology Planning Project of Sichuan Province, China (Grant No. 14JC0798), Educational Commission of Sichuan Province, China (Grant No. 15ZA0155, 16ZA0187), Science and Technology Program of Luzhou, China (Grant No. 2015LZCYD-S09(5/8), 2015-S-43, 2016LZXNYD-T03), Key Development Program of Southwest Medical University (Grant No. 2010ZD010), and Science and Technology Program of Affiliated Hospital of Southwest Medical University (Grant No. 15114).

\section{CONFLICTS OF INTEREST}

There is no conflicts of interest.

\section{REFERENCES}

1. Jacobs BL, Azmitia EC. Structure and function of the brain serotonin system. Physiol Rev. 1992; 72:165-229.

2. Meltzer HY, Roth BL. Lorcaserin and pimavanserin: emerging selectivity of serotonin receptor subtype-targeted drugs. J Clin Invest. 2013; 123:4986-4991.

3. Berger M, Gray JA, Roth BL. The expanded biology of serotonin. Annu Rev Med. 2009; 60:355-366.

4. Barnes NM, Sharp T. A review of central 5-HT receptors and their function. Neuropharmacology. 1999; 38:1083-1152.

5. Hoyer D, Hannon JP, Martin GR. Molecular, pharmacological and functional diversity of 5-HT receptors. Pharmacol Biochem Behav. 2002; 71:533-554.

6. Pierce KL, Premont RT, Lefkowitz RJ. Seventransmembrane receptors. Nat Rev Mol Cell Bio. 2002; 3:639-650.

7. Albert PR, Zhou QY, Van Tol HH, Bunzow JR, Civelli O. Cloning, functional expression, and mRNA tissue distribution of the rat 5-hydroxytryptamine1A receptor gene. J Biol Chem. 1990; 265:5825-5832. 
8. Kobilka BK, Frielle T, Collins S, Yang-Feng T, Kobilka TS, Francke U, Lefkowitz RJ, Caron MG. An intronless gene encoding a potential member of the family of receptors coupled to guanine nucleotide regulatory proteins. Nature. 1987; 329:75-79.

9. Boess FG, Martin IL. Molecular biology of 5-HT receptors. Neuropharmacology. 1994; 33:275-317.

10. Lanfumey L, Hamon M. 5-HT1 receptors. Curr Drug Targets CNS Neurol Disord. 2004; 3:1-10.

11. Matthiessen L, Kia HK, Daval G, Riad M, Hamon M, Vergé D. Immunocytochemical localization of serotonin1A receptors in the rat immature cerebellum. Neuroreport. 1993; 4:763-766.

12. Kung MP, Zhuang ZP, Frederick D, Kung HF. In vivo binding of [123I]4-(2'-methoxyphenyl)-1-[2'-(N-2"pyridinyl)-P-iodobenzamido-] ethyl-piperazine, p-MPPI, to 5-HT1A receptors in rat brain. Synapse. 1994; 18:359-366.

13. Blier P, Ward NM. Is there a role for 5-HT1A agonists in the treatment of depression? Biol Psychiat. 2003; 53:193-203.

14. McCorvy JD, Roth BL. Structure and function of serotonin $\mathrm{G}$ protein-coupled receptors. Pharmacol Ther. 2015; 150:129-142.

15. Wang C, Jiang Y, Ma J, Wu H, Wacker D, Katritch V, Han GW, Liu W, Huang XP, Vardy E, McCorvy JD, Gao X, Zhou XE, et al. Structural basis for molecular recognition at serotonin receptors. Science. 2013; 340:610-614.

16. Yuan S, Peng Q, Palczewski K, Vogel H, Filipek S. Mechanistic studies on the stereoselectivity of the serotonin 5-HT1A receptor. Angew Chem Int Ed. 2016; 55:8661-8665.

17. Hooff PVD, Galvan M. Actions of 5-hydroxytryptamine and 5-HT1A receptor ligands on rat dorso-lateral septal neurons in vitro. Br J Pharmacol. 1992; 106:893-899.

18. Schoeffter P, Hoyer D. Centrally acting hypotensive agents with affinity for 5-HT1A binding sites inhibit forskolinstimulated adenylate cyclase activity in calf hippocampus. Br J Pharmacol. 1988; 95:975-985.

19. Tanaka H, Tatsuno T, Shimizu H, Hirose A, Kumasaka Y, Nakamura M. Effects of tandospirone on second messenger systems and neurotransmitter release in the rat brain. Gen Pharmacol. 1995; 26:1765-1772.

20. Koek W, Patoiseau J, Assié MB, Cosi C, Kleven MS, Dupont-Passelaigue E, Carilla-Durand E, Palmier C, Valentin J, John G, Pauwels PJ, Tarayre JP, Colpaert FC. F 11440, a potent, selective, high efficacy 5-HT1A receptor agonist with marked anxiolytic and antidepressant potential. J Pharmacol Exp Ther. 1998; 287:266-283.

21. Hamik A, Oksenberg D, Fischette C, Peroutka SJ. Analysis of tandospirone (SM-3997) interactions with neurotransmitter receptor binding sites. Biol Psychiatry. 1990; 28:99-109.
22. Patane MA, DiPardo RM, Price RP, Chang RS, Ransom RW, O'Malley SS, Di Salvo J, Bock MG. Selective $\alpha-1$ A adrenergic receptor antagonists. Effects of pharmacophore regio- and stereochemistry on potency and selectivity. Bioorg Med Chem Lett. 1998; 8:2495-2500.

23. Tunnicliff G. Molecular basis of buspirone's anxiolytic action. Pharmacol Toxicol. 1991; 69:149-156.

24. Tanaka H, Shimizu H, Kumasaka Y, Hirose A, Tatsuno T, Nakamura M. Autoradiographic localization and pharmacological characterization of $[3 \mathrm{H}]$ tandospirone binding sites in the rat brain. Brain Res. 1991; 546:181-189.

25. Shimizu H, Tatsuno T, Tanaka H, Hirose A, Araki Y, Nakamura M. Serotonergic mechanisms in anxiolytic effect of tandospirone in the Vogel conflict test. Jpn J Pharmacol. 1992; 59:105-112.

26. Kessler RC. The global burden of anxiety and mood disorders: putting the European Study of the Epidemiology of Mental Disorders (ESEMeD) findings into perspective. J Clin Psychiatry. 2007; 68:10-19.

27. Garakani A, Mathew SJ, Charney DS. Neurobiology of anxiety disorders and implications treatment. Mt Sinai J Med. 2006; 73:941-949.

28. Wittchen H, Jacobi F, Rehm J, Gustavsson A, Svensson M, Jonsson B, Olesen J, Allgulander C, Alonso J, Faravelli C, Fratiglioni L, Jennum P, Lieb R, et al. The size and burden of mental disorders and other disorders of the brain in Europe 2010. Eur Neuropsychopharmacol. 2011; 21:655-679.

29. Kessler RC, Ormel J, Petukhova M, McLaughlin KA, Green JG, Russo LJ, Stein DJ, Zaslavsky AM, AguilarGaxiola S, Alonso J, Andrade L, Benjet C, Girolamo GD, et al. Development of lifetime comorbidity in the World Health Organization world mental health surveys. Arch Gen Psychiatry. 2011; 68:90-100.

30. Ormel J, Petukhova M, Chatterji S, Aguilargaxiola $\mathrm{S}$, Alonso J, Angermeyer MC, Bromet EJ, Burger H, Demyttenaere K, Girolamo GD, Haro JM, Hwang I, Karam E, et al. Disability and treatment of specific mental and physical disorders across the world. Br J Psychiatry. 2008; 192:368-375.

31. Nishitsuji K, To H, Shimizu T, Yanase Y, Yamada T, Hara C, Mine K, Higuchi S. The pharmacokinetics and pharmacodynamics of tandospirone in rats exposed to conditioned fear stress. Eur Neuropsychopharm. 2006; 16:376-382.

32. Evans SM, Troisi JR, Griffiths RR. Tandospirone and alprazolam: comparison of behavioral effects and abuse liability in humans. J Pharmacol Exp Ther. 1994; 271:683-694.

33. Vaswani M, Linda FK, Ramesh S. Role of selective serotonin reuptake inhibitors in psychiatric disorders: a comprehensive review. Prog Neuropsychopharmacol Biol Psychiatry. 2003; 27:85-102. 
34. Pollard GT, Nanry KP, Howard JL. Effects of tandospirone in three behavioral tests for anxiolytics. Eur J Pharmacol. 1992; 221:297-305.

35. Chessick CA, Allen MH, Thase M, Batista Miralha da Cunha AB, Kapczinski FF, de Lima MS, dos Santos Souza JJ. Azapirones for generalized anxiety disorder. Cochrane Database Syst Rev. 2006; 3:CD006115.

36. Nishitsuji K, To H, Murakami Y, Kodama K, Kobayashi D, Yamada T, Kubo C, Mine K. Tandospirone in the treatment of generalised anxiety disorder and mixed anxietydepression: results of a comparatively high dosage trial. Clin Drug Investig. 2004; 24:121-126.

37. Raymond JR, Mukhin YV, Gettys TW, Garnovskaya MN. The recombinant 5-HT1A receptor: G protein coupling and signalling pathways. Br J Pharmacol. 1999; 127:1751-1764.

38. Yabuuchi K, Tagashira R, Ohno Y. Effects of tandospirone, a novel anxiolytic agent, on human 5-HT1A receptors expressed in Chinese hamster ovary cells ( $\mathrm{CHO}$ cells). Biogenic Amines. 2004; 18:319-328.

39. Polter AM, Li X. 5-HT1A receptor-regulated signal transduction pathways in brain. Cell Signal. 2010; 22:1406-1412.

40. Godbout R, Chaput Y, Blier P, de Montigny C. Tandospirone and its metabolite, 1-(2-pyrimidinyl)-piperazine-I. Effects of acute and long-term administration of tandospirone on serotonin neurotransmission. Neuropharmacology. 1991; 30:679-690.

41. Tada K, Kasamo K, Ueda N, Suzuki T, Kojima T, Ishikawa K. Anxiolytic 5-hydroxytryptamine1A agonists suppress firing activity of dorsal hippocampus CA1 pyramidal neurons through a postsynaptic mechanism: single-unit study in unanesthetized, unrestrained rats. J Pharmacol Exp Ther. 1999; 288:843-848.

42. Oshima T, Kasuya Y, Terazawa E, Nagase K, Saitoh Y, Dohi $\mathrm{S}$. The anxiolytic effects of the 5-hydroxytryptamine-1A agonist tandospirone before otolaryngologic surgery. Anesth Analg. 2001; 93:1214-1216.

43. Lizawa A, Oshima T, Kasuya Y, Dohi S. Oral tandospirone and clonidine provide similar relief of preoperative anxiety. Can J Anesth. 2004; 51:668-671.

44. Nishikawa H, Inoue T, Izumi T, Koyama T. Synergistic effects of tandospirone and selective serotonin reuptake inhibitors on the contextual conditioned fear stress response in rats. Eur Neuropsychopharmacol. 2007; 17:643-650.

45. Nishikawa $H$, Inoue $T$, Masui $T$, Izumi $T$, Nakagawa $\mathrm{S}$, Koyama T. Pharmacokinetic interaction between tandospirone and fluvoxamine in the rat contextual conditioned fear stress model and its functional consequence: Involvement of cytochrome P450 3A4. Psychiatry Clin Neurosci. 2008; 62:591-596.

46. Nishikawa H, Inoue T, Masui T, Izumi T, Koyama T. Effects of cytochrome P450 (CYP) 3A4 inhibitors on the anxiolytic action of tandospirone in rat contextual conditioned fear.
Prog Neuropsychopharmacol Biol Psychiatry. 2007; 31:926-931.

47. Saito Y, Matsumoto M, Yanagawa Y, Hiraide S, Inoue S, Kubo Y, Shimamura K, Togashi H. Facilitation of fear extinction by the 5-HT1A receptor agonist tandospirone: Possible involvement of dopaminergic modulation. Synapse. 2013; 67:161-170.

48. Li X. Using the conditioned fear stress (CFS) animal model to understand the neurobiological mechanisms and pharmacological treatment of anxiety. Shanghai Arch Psychiatry. 2012; 24:241-249.

49. Huang X, Li C, Li WH, Luo YL, Wang B, Zhang W, Gan JJ, Ji JL. Clinical evaluation of the efficacy and safety of tandospirone versus sertraline monotherapy for social anxiety disorder: a randomized open-label trial. Hum Psychopharmacol. 2013; 28:594-599.

50. Kessler RC, Berglund P, Demler O, Jin R, Koretz D, Merikangas KR, Rush AJ, Walters EE, Wang PS. The epidemiology of major depressive disorder: results from the National Comorbidity Survey Replication (NCS-R). JAMA. 2003; 289:3095-3105.

51. Alison B, Fadela C. "Depression: let's talk" says WHO, as depression tops list of causes of ill health. World Health Organization, media center. 2017.

52. Papakostas GI, Fava M. Does the probability of receiving placebo influence clinical trial outcome? A meta-regression of double-blind, randomized clinical trials in MDD. Eur Neuropsychopharmacol. 2009; 19:34-40.

53. Mahar I, Bambico FR, Mechawar N, Nobrega JN. Stress, serotonin, and hippocampal neurogenesis in relation to depression and antidepressant effects. Neurosci Biobehav Rev. 2014; 38:173-192.

54. Wieland S, Lucki I. Antidepressant-like activity of 5-HT1A agonists measured with the forced swimming test. Psychopharmacology. 1990; 101:497-504.

55. Masuda Y, Ohnuma S, Sugiyama T. Alpha 2-adrenoceptor activity induces the antidepressant-like glycolipid in mouse forced swimming. Methods Find Exp Clin Pharmacol. 2001; 23:19-21.

56. Masuda Y, Sugiyama T. The effect of globopentaosylceramide on a depression model, mouse forced swimming. Tohoku J Exp Med. 2000; 191:47-54.

57. Murata Y, Yanagihara Y, Mori M, Mine K, Enjoji M. Chronic treatment with tandospirone, a serotonin $1 \mathrm{~A}$ receptor partial agonist, inhibits psychosocial stress-induced changes in hippocampal neurogenesis and behavior. J Affect Disord. 2015; 180:1-9.

58. Trivedi MH, Fava M, Wisniewski SR, Thase ME, Quitkin F, Warden D, Ritz L, Nierenberg AA, Lebowitz BD, Biggs MM, Luther JF, Shores-Wilson K, Rush AJ. Medication augmentation after the failure of SSRIs for depression. N Engl J Med. 2006; 354:1243-1252.

59. Yusuke M, Yuko M, Daisuke K, Chiharu K, Kazunori M. The efficacy of combination therapy with paroxetine and 
tandospirone for depressive and anxiety disorders. Int Clin Psychopharm. 2006; 21:A14.

60. Yoshino T, Nisijima K, Katoh S, Yui K, Nakamura M. Tandospirone potentiates the fluoxetine-induced increases in extracellular dopamine via 5-HT1A receptors in the rat medial frontal cortex. Neurochem Int. 2002; 40:355-360.

61. Malberg JE, Eisch AJ, Nestler EJ, Duman RS. Chronic antidepressant treatment increases neurogenesis in adult rat hippocampus. J Neurosci. 2000; 20:9104-9110.

62. Mori M, Murata Y, Matsuo A, Takemoto T, Mine K. Chronic treatment with the 5-HT1A receptor partial agonist tandospirone increases hippocampal neurogenesis. Neurol Ther. 2014; 3:67-77.

63. Uehara T, Matsuoka T, Itoh H, Sumiyoshi T. Chronic treatment with tandospirone, a 5-HT(1A) receptor partial agonist, suppresses footshock stress-induced lactate production in the prefrontal cortex of rats. Pharmacol Biochem Behav. 2013; 113:1-6.

64. Yamada K, Yagi G, Kanba S. Clinical efficacy of tandospirone augmentation in patients with major depressive disorder: a randomized controlled trial. Psychiatry Clin Neuroscie. 2003; 57:183-187.

65. Masuda Y, Akagawa Y, Hishikawa Y. Effect of serotonin 1A agonist tandospirone on depression symptoms in senile patients with dementia. Hum Psychopharmacol. 2002; 17:191-193.

66. Holshoe JM. Antidepressants and sleep: a review. Perspect Psychiatr Care. 2009; 45:191-197.

67. Breslau N, Roth T, Rosenthal L, Andreski P. Sleep disturbance and psychiatric disorders: a longitudinal epidemiological study of young adults. Biol Psychiatry. 1996; 39:411-418.

68. Buysse DJ. Chronic insomnia. Am J Psychiat. 2008; 165:678-686.

69. Ohayon MM, Roth T. Place of chronic insomnia in the course of depressive and anxiety disorders. J Psychiatr Res. 2003; 37:9-15.

70. Tsutsui R, Shinomiya K, Sendo T, Kitamura Y, Kamei C. Effects of the 5-HT1A receptor agonist tandospirone on ACTH-Induced sleep disturbance in rats. Biol Pharm Bull. 2015; 38:884-888.

71. Kishi Y. Paroxetine-induced bruxism effectively treated with tandospirone. J Neuropsychiatry Clin Neurosci. 2007; 19:90-91.

72. Lawlor BA. Behavioral and psychological symptoms in dementia: the role of atypical antipsychotics. J Clinical Psychiatry. 2004; 65:5-10.

73. Lai MK, Tsang SW, Francis PT, Esiri MM, Keene J, Hope $\mathrm{T}$, Chen CP. Reduced serotonin 5-HT1A receptor binding in the temporal cortex correlates with aggressive behavior in Alzheimer disease. Brain Res. 2003; 974:82-87.

74. Truchot L, Costes SN, Zimmer L, Laurent B, Bars DL, Thomasanterion C, Croisile B, Mercier B, Hermier M, Vighetto A, Krolaksalmon P. Up-regulation of hippocampal serotonin metabolism in mild cognitive impairment. Neurology. 2007; 69:1012-1017.

75. Sato S, Mizukami K, Asada T. A preliminary openlabel study of 5-HT1A partial agonist tandospirone for behavioural and psychological symptoms associated with dementia. Int J Neuropsychopharmacol. 2007; 10:281-283.

76. Lang AE, Lozano AM. Parkinson's disease. First of two parts. N Engl J Med. 1998; 339:1044-1053.

77. Nomoto M, Iwata S, Kaseda S. A 5-HT1A receptor agonist, tandospirone improves gait disturbance of patients with Parkinson's disease. J Mov Disord Disability. 1997; 7:65-70.

78. Yoshida K, Sugita T, Higuchi H, Hishikawa Y. Effect of tandospirone on tardive dyskinesia and parkinsonian symptoms. Eur Psychiatry. 1998; 13:421-422.

79. Miyata S, Hamamura T, Yoshinaga J, Nakamura Y, Imamura T, Hikiji A, Kuroda S. Amelioration of frozen gait by tandospirone, a serotonin $1 \mathrm{~A}$ agonist, in a patient with pure akinesia developing resistance to L-threo-3,4dihydroxyphenylserine. Clin Neuropharmacol. 2001; 24:232-234.

80. Ishibashi T, Ohno Y. Antiparkinsonian actions of a selective 5-HT1A agonist, tandospirone, in rats. Biogenic Amines. 2004; 18:329-338.

81. Matsubara K, Shimizu K, Suno M, Ogawa K, Awaya T, Yamada T, Noda T, Satomi M, Ohtaki K, Chiba K, Tasaki Y, Shiono H. Tandospirone, a 5-HT1A agonist, ameliorates movement disorder via non-dopaminergic systems in rats with unilateral 6-hydroxydopamine-generated lesions. Brain Res. 2006; 1112:126-133.

82. Ohno Y, Shimizu S, Imaki J. Effects of tandospirone, a 5-HT1 A agonistic anxiolytic agent, on haloperidol-induced catalepsy and forebrain Fos expression in mice. J Pharmacol Sci. 2009; 109:593-599.

83. Ohno Y, Shimizu S, Imaki J, Ishihara S, Sofue N, Sasa M, Kawai Y. Evaluation of the antibradykinetic actions of 5-HT1A agonists using the mouse pole test. Prog Neuropsychopharmacol Biol Psychiatry. 2008; 32:1302-1307.

84. Costall B, Naylor RJ, Pycock C. Non-specific supersensitivity of striatal dopamine receptors after 6-hydroxydopamine lesion of the nigrostriatal pathway. Eur J Pharmacol. 1976; 35:276-283.

85. Galeffi F, Bianchi L, Bolam JP, Della CL. The effect of 6-hydroxydopamine lesions on the release of amino acids in the direct and indirect pathways of the basal ganglia: a dual microdialysis probe analysis. Eur J Neurosci. 2003; 18:856-868.

86. Mignon LJ, Wolf WA. 8-hydroxy-2-(di-n-propylamino) tetralin reduces striatal glutamate in an animal model of Parkinson's disease. Neuroreport. 2005; 16:699-703.

87. Antonelli T, Fuxe K, Tomasini MC, Bartoszyk GD, Seyfried CA, Tanganelli S, Ferraro L. Effects of sarizotan on the corticostriatal glutamate pathways. Synapse. 2005; 58:193-199. 
88. Kannari K, Kurahashi K, Tomiyama M, Maeda T, Arai A, Baba M, Suda T, Matsunaga M. Tandospirone citrate, a selective 5-HT1A agonist, alleviates L-DOPA-induced dyskinesia in patients with Parkinson's disease. [Article in Japanese]. No To Shinkei. 2002; 54:133-137.

89. Iderberg H, McCreary AC, Varney MA, Cenci MA, Newman-Tancredi A. Activity of serotonin 5-HT1A receptor 'biased agonists' in rat models of Parkinson's disease and L-DOPA-induced dyskinesia. Neuropharmacology. 2015; 93:52-67.

90. Singhal BS, Lalkaka JA, Sheth A. Management of anxiety and depression in Parkinson's disease, In Mizuno Y., Fisher A., Hanin I. (eds) Mapping the progress of Alzheimer's and Parkinson's disease. Adv Behav Biol. 2002; 51:417-422.

91. Ohno Y. Tandospirone citrate, a new serotonergic anxiolytic agent: a potential use in Parkinson's disease. In: Mizuno Y., Fisher A., Hanin I. (eds) Mapping the progress of Alzheimer's and Parkinson's disease. Adv Behav Biol. 2002; 51:423-428.

92. Meltzer HY. The mechanism of action of novel antipsychotic drugs. Schizophrenia Bull. 1991; 17:263-287.

93. Kapur S, Remington G. Atypical antipsychotics: new directions and new challenges in the treatment of schizophrenia. Annu Rev Med. 2001; 52:503-517.

94. Mohamed S, Paulsen JS, O'Leary D, Arndt S, Andreasen N. Generalized cognitive deficits in schizophrenia: a study of first-episode patients. Arch Gen Psychiatry. 1999; 56:749-754.

95. Mcgurk SR, Meltzer HY. The role of cognition in vocational functioning in schizophrenia. Schizophr Res. 2000; $45: 175-184$

96. Newman-Tancredi A, Gavaudan S, Conte C, Chaput C, Touzard M, Verrièle L, Audinot V, Millan MJ. Agonist and antagonist actions of antipsychotic agents at 5-HT1A receptors: a [35S]GTPgammaS binding study. Eur J Pharmacol. 1998; 355:245-256.

97. Shapiro DA, Renock S, Arrington E, Chiodo LA, Liu LX, Sibley DR, Roth BL, Mailman R. Aripiprazole, a novel atypical antipsychotic drug with a unique and robust pharmacology. Neuropsychopharmacology. 2003; 28:1400-1411.

98. Sumiyoshi T, Matsui M, Yamashita I, Nohara S, Uehara T, Kurachi M, Meltzer HY. Effect of adjunctive treatment with serotonin-1A agonist tandospirone on memory functions in schizophrenia. J Clin Psychopharmacol. 2000; 20:386-388.

99. Sumiyoshi T, Matsui M, Yamashita I, Nohara S, Kurachi M, Uehara T, Sumiyoshi S, Sumiyoshi C, Meltzer HY. The Effect of tandospirone, a serotonin1 A agonist, on memory function in schizophrenia. Biological Psychiatry. 2001; 49:861-868.

100. Sumiyoshi T, Matsui M, Nohara S, Yamashita I, Kurachi M, Sumiyoshi C, Jayathilake K, Meltzer HY. Enhancement of cognitive performance in schizophrenia by addition of tandospirone to neuroleptic treatment. Am J Psychiatry. 2001; 158:1722-1725.

101. Higuchi Y, Sumiyoshi T, Kawasaki Y, Ito T, Seo T, Suzuki M. Effect of tandospirone on mismatch negativity and cognitive performance in schizophrenia: a case report. J Clin Psychopharmacol. 2010; 30:732-734.

102. Sumiyoshi T, Higuchi Y, Matsui M, Arai H, Takamiya C, Meltzer HY, Kurachi M. Effective adjunctive use of tandospirone with perospirone for enhancing verbal memory and quality of life in schizophrenia. Prog Neuropsychopharmacol Biol Psychiatry. 2007; 31:965-967.

103. Yasuno F, Suhara T, Nakayama T, Ichimiya T, Okubo Y, Takano A, Ando T, Inoue M, Maeda J, Suzuki K. Inhibitory effect of hippocampal 5-HT1A receptors on human explicit memory. Am J Psychiatry. 2003; 160:334-340.

104. Gunduz-Bruce H. The acute effects of NMDA antagonism: from the rodent to the human brain. Brain Res Rev. 2009; 60:279-286.

105. Horiguchi M, Hannaway KE, Adelekun AE, Jayathilake K, Meltzer HY. Prevention of the phencyclidine-induced impairment in novel object recognition in female rats by co-administration of lurasidone or tandospirone, a 5-HT1A partial agonist. Neuropsychopharmacology. 2012; 37:2175-2183.

106. Choi YK, Snigdha S, Shahid M, Neill JC, Tarazi FI. Subchronic effects of phencyclidine on dopamine and serotonin receptors: implications for schizophrenia. J Mol Neurosci. 2009; 38:227-235.

107. Amargós-Bosch M, López-Gil X, Artigas F, Adell A. Clozapine and olanzapine, but not haloperidol, suppress serotonin efflux in the medial prefrontal cortex elicited by phencyclidine and ketamine. Int J Neuropsychopharmacol. 2006; 9:565-573.

108. Burnet PW, Eastwood SL, Harrison PJ. [3H]WAY-100635 for 5-HT1A receptor autoradiography in human brain: a comparison with [3H]8-OH-DPAT and demonstration of increased binding in the frontal cortex in schizophrenia. Neurochem Int. 1997; 30:565-574.

109. Kasper S, Tauscher J, Willeit M, Stamenkovic M, Neumeister A, Küfferle B, Barnas C, Stastny J, PraschakRieder N, Pezawas L, de Zwaan M, Quiner S, Pirker $\mathrm{W}$, et al. Receptor and transporter imaging studies in schizophrenia, depression, bulimia and Tourette's disorder-implications for psychopharmacology. World J Biol Psychiatry. 2002; 3:133-146.

110. Baba S, Murai T, Nakako T, Enomoto T, Ono M, Shimizu I, Ikeda K. The serotonin 5-HT1A receptor agonist tandospirone improves executive function in common marmosets. Behav Brain Res. 2015; 287:120-126.

111. Uehara T, Itoh H, Matsuoka T, Rujescu D, Genius J, Seo T, Sumiyoshi T. Effect of transient blockade of n-methylD-aspartate receptors at neonatal stage on stress-induced lactate metabolism in the medial prefrontal cortex of adult 
rats: role of 5-HT1A receptor agonism. Synapse. 2012; 66:408-417.

112. Bubenikova-Valesova V, Svoboda J, Horacek J, Sumiyoshi T. Effect of tandospirone, a serotonin-1A receptor partial agonist, on information processing and locomotion in dizocilpine-treated rats. Psychopharmacology. 2010; 212:267-276.

113. Miller LG, Thompson ML, Byrnes JJ, Greenblatt DJ, Shemer A. Kinetics, brain uptake, and receptor binding of tandospirone and its metabolite 1-(2-pyrimidinyl)piperazine. J Clin Psychopharmacol. 1992; 12:341-345.

114. Newman-Tancredi A, Nicolas JP, Audinot V, Gavaudan S, Verrièle L, Touzard M, Chaput C, Richard N, Millan MJ. Actions of alpha2 adrenoceptor ligands at alpha2A and 5-HT1A receptors: the antagonist, atipamezole, and the agonist, dexmedetomidine, are highly selective for alpha2A adrenoceptors. Naunyn Schmiedebergs Arch pharmacol. 1998; 358:197-206.

115. Ohmura Y, Kumamoto H, Tsutsui-Kimura I, Minami M, Izumi T, Yoshida T, Yoshioka M. Tandospirone suppresses impulsive action by possible blockade of the 5-HT1A receptor. J Pharmacol Sci. 2013; 122:84-92.

116. Jin YH, Akaike N. Tandospirone-induced $\mathrm{K}+$ current in acutely dissociated rat dorsal raphe neurones. $\mathrm{Br} \mathrm{J}$ pharmacol. 1998; 124:897-904.

117. Sullivan NR, Crane JW, Damjanoska KJ, Carrasco GA, D'Souza DN, Garcia F, Van de Kar LD. Tandospirone activates neuroendocrine and ERK (MAP kinase) signaling pathways specifically through 5-HT1A receptor mechanisms in vivo. Naunyn Schmiedebergs Arch Pharmacol. 2005; 371:18-26.

118. Hensler JG. Regulation of 5-HT1A receptor function in brain following agonist or antidepressant administration. Life Sci. 2003; 72:1665-1682.

119. Sumiyoshi T, Higuchi Y. Facilitative effect of serotonin(1A) receptor agonists on cognition in patients with schizophrenia. Curr Med Chem. 2013; 20:357-362.

120. Huang M, Panos JJ, Kwon S, Oyamada Y, Rajagopal L, Meltzer HY. Comparative effect of lurasidone and blonanserin on cortical glutamate, dopamine, and acetylcholine efflux: role of relative serotonin (5-HT) 2A and DA D2 antagonism and 5-HT1A partial agonism. J Neurochem. 2014; 128:938-949.

121. Horiguchi M, Meltzer HY. The role of 5-HT receptors in phencyclidine (PCP)-induced novel object recognition (NOR) deficit in rats. Psychopharmacology. 2012; 221:205-215.

122. Duman RS. Depression: a case of neuronal life and death? Biol Psychiatry. 2004; 56:140-145.

123. Samuels BA, Hen R. Neurogenesis and affective disorders. Eur J Neurosci. 2011; 33:1152-1159.

124. Lazarov O, Hollands C. Hippocampal neurogenesis: learning to remember. Prog Neurobiol. 2016; 138-140:1-8.
125. Mori K, Togashi H, Kojima T, Matsumoto M, Ohashi $\mathrm{S}$, Ueno K, Yoshioka M. Different effects of anxiolytic agents, diazepam and 5-HT(1A) agonist tandospirone, on hippocampal long-term potentiation in vivo. Pharmacol Biochem Behav. 2001; 69:367-372.

126. Bliss TV, Collingridge GL. Asynaptic model of memory: long-term potentiation in the hippocampus. Nature. 1993; 361:31-39.

127. Aubert A, Costalat R, Magistretti PJ, Pellerin L. Brain lactate kinetics: Modeling evidence for neuronal lactate uptake upon activation. Proc Natl Acad Sci U S A. 2005; 102:16448-16453.

128. O'Brien J, Kla KM, Hopkins IB, Malecki EA, McKenna MC. Kinetic parameters and lactate dehydrogenase isozyme activities support possible lactate utilization by neurons. Neurochem Res. 2007; 32:597-607.

129. Laughton JD, Bittar P, Charnay Y, Pellerin L, Kovari E, Magistretti PJ, Bouras C. Metabolic compartmentalization in the human cortex and hippocampus: evidence for a celland region-specific localization of lactate dehydrogenase 5 and pyruvate dehydrogenase. BMC Neurosci. 2007; 8:35.

130. Pellerin L, Bouzier-Sore AK, Aubert A, Serres S, Merle M, Costalat R, Magistretti PJ. Activity-dependent regulation of energy metabolism by astrocytes: an update. Glia. 2007; 55:1251-1262.

131. Wyss MT, Jolivet R, Buck A, Magistretti PJ, Weber B. In vivo evidence for lactate as a neuronal energy source. J Neurosci. 2011; 31:7477-7485.

132. Uehara T, Sumiyoshi T, Matsuoka T, Itoh H, Kurachi M. Role of 5-HT(1A) receptors in the modulation of stressinduced lactate metabolism in the medial prefrontal cortex and basolateral amygdala. Psychopharmacology. 2006; 186:218-225.

133. Calcagno E, Carli M, Invernizzi RW. The 5-HT(1A) receptor agonist 8-OH-DPAT prevents prefrontocortical glutamate and serotonin release in response to blockade of cortical NMDA receptors. J Neurochem. 2006; 96:853-860.

134. Wang C, McInnis J, Ross-Sanchez M, Shinnick-Gallagher P, Wiley JL, Johnson KM. Long-term behavioral and neurodegenerative effects of perinatal phencyclidine administration: implications for schizophrenia. Neuroscience. 2001; 107:535-550.

135. Stefani MR, Moghaddam B. Transient N-methyl-Daspartate receptor blockade in early development causes lasting cognitive deficits relevant to schizophrenia. Biol Psychiatry. 2005; 57:433-436.

136. Harris LW, Sharp T, Gartlon J, Jones DN, Harrison PJ. Long-term behavioural, molecular and morphological effects of neonatal NMDA receptor antagonism. Eur $\mathrm{J}$ Neurosci. 2003; 18:1706-1710.

137. Wang C, McInnis J, West JB, Bao J, Anastasio N, Guidry JA, Ye Y, Salvemini D, Johnson KM. Blockade of phencyclidine-induced cortical apoptosis and deficits in 
prepulse inhibition by M40403, a superoxide dismutase mimetic. J Pharmacol Exp Ther. 2003; 304:266-271.

138. Lladó-Pelfort L, Santana N, Ghisi V, Artigas F, Celada P. 5-HT1A receptor agonists enhance pyramidal cell firing in prefrontal cortex through a preferential action on GABA interneurons. Cereb Cortex. 2012; 22:1487-1497.
139. Uehara T, Matsuoka T, Sumiyoshi T. Tandospirone, a 5-HT1A partial agonist, ameliorates aberrant lactate production in the prefrontal cortex of rats exposed to blockade of N-methy-D-aspartate receptors; Toward the therapeutics of cognitive impairment of schizophrenia. Front Behav Neurosci. 2014; 8:291. 